\title{
Refined Qingkailing Protects MCAO Mice from Endoplasmic Reticulum Stress-Induced Apoptosis with a Broad Time Window
}

\author{
Fafeng Cheng, ${ }^{1}$ Xianggen Zhong, ${ }^{1}$ Yi Lu, ${ }^{1}$ Xueqian Wang, ${ }^{1}$ Wenting Song, ${ }^{2}$ Shaoying Guo, \\ Xiaotong Wang, ${ }^{1}$ Dantong Liu, ${ }^{1}$ and Qingguo Wang ${ }^{1}$ \\ ${ }^{1}$ College of Basic Medicine, Beijing University of Chinese Medicine, Beijing 100029, China \\ ${ }^{2}$ Xiyuan Hospital, China Academy of Chinese Medical Sciences, Beijing 100091, China \\ Correspondence should be addressed to Qingguo Wang, wangqg8558@sina.com
}

Received 13 November 2011; Revised 2 January 2012; Accepted 3 January 2012

Academic Editor: Hao Xu

Copyright () 2012 Fafeng Cheng et al. This is an open access article distributed under the Creative Commons Attribution License, which permits unrestricted use, distribution, and reproduction in any medium, provided the original work is properly cited.

In the current study, we are investigating effect of refined QKL on ischemia-reperfusion-induced brain injury in mice. Methods. Mice were employed to induce ischemia-reperfusion injury of brain by middle cerebral artery occlusion (MCAO). RQKL solution was administered with different doses $(0,1.5,3$, and $6 \mathrm{~mL} / \mathrm{kg}$ body weight $)$ at the same time of onset of ischemia, and with the dose of $1.5 \mathrm{~mL} / \mathrm{kg}$ at different time points $(0,1.5,3,6$, and $9 \mathrm{~h}$ after MCAO). Neurological function and brain infarction were examined and cell apoptosis and ROS at prefrontal cortex were evaluated $24 \mathrm{~h}$ after MCAO, and western blot and intracellular calcium were also researched, respectively. Results. RQKL of all doses can improve neurological function and decrease brain infarction, and it performed significant effect in $0,1.5,3$, and $6 \mathrm{~h}$ groups. Moreover, RQKL was able to reduce apoptotic process by reduction of caspase-3 expression, or restraint of eIF2a phosphorylation and caspase-12 activation. It was also able to reduce ROS and modulate intracellular calcium in the brain. Conclusion. RQKL can prevent ischemic-induced brain injury with a time window of $6 \mathrm{~h}$, and its mechanism might be related to suppress ER stress-mediated apoptotic signaling.

\section{Introduction}

Ischemic stroke is a life-threatening disease featured by high morbidity and mortality. Investigating new drugs is a hotspot and the difficulty of ischemic stroke research. The committee of the Stroke Therapy Academic Industry Roundtable proposed that studies of drugs for brain ischemia should pay attention to their pharmaceutical window $[1,2]$. In clinical practice, treatment for stroke patients is always delayed after onset, and the time at which treatment is administered is highly correlated with therapeutic effect.

Qingkailing (QKL) injection was originally prepared by the Beijing University of Chinese Medicine in the 1970s, by modifying a traditional Chinese medicine, Angongniuhuang pills, composed of Radix isatidis, Flos Lonicerae, Concha Margaritifera Usta, baicalin, Fructus gardeniae, cholic acid, hyodeoxycholic acid, and Cornu Bubali [3]. It has been extensively used to treat the acute stages of cerebrovascular disease and has performed excellently in improving neurological function [4]. Animal experiments have shown that
QKL injection can promote endothelial nitric oxide synthase expression, reduce calcium overload, regulate matrix metallopeptidase 9 expression, and inhibit inflammation in the murine model of cerebral ischemia/reperfusion [5-8]. However, QKL is confronted with handicaps from drug safety regulations in recent years, which has severely embarrassed its clinical application [9]. QKL being composed of complex components is the central problem of quality stabilization and clinic safety. Based on this, we developed refined Qingkailing (RQKL), aimed at acute ischemic stroke.

Refined Qingkailing (RQKL) injection consists of cholic acid, hyodeoxycholic acid, baicalin, and jasminoidin (Figure 1). Baicalin is derived from the dried root of Scutellaria baicalensis Georgi which is named as Huang Qin in traditional Chinese medicine (TCM), and jasminoidin is derived from the dried fruit of Gardenia jasminoides Ellis which is named as $\mathrm{Zhi} \mathrm{Zi}$ in TCM. Both herbs provide excellent antioxidative and anti-inflammation effects [1013]. Cholic acid and hyodeoxycholic acid are both bile acids and have neuron-protective effects $[14,15]$. Furthermore, 


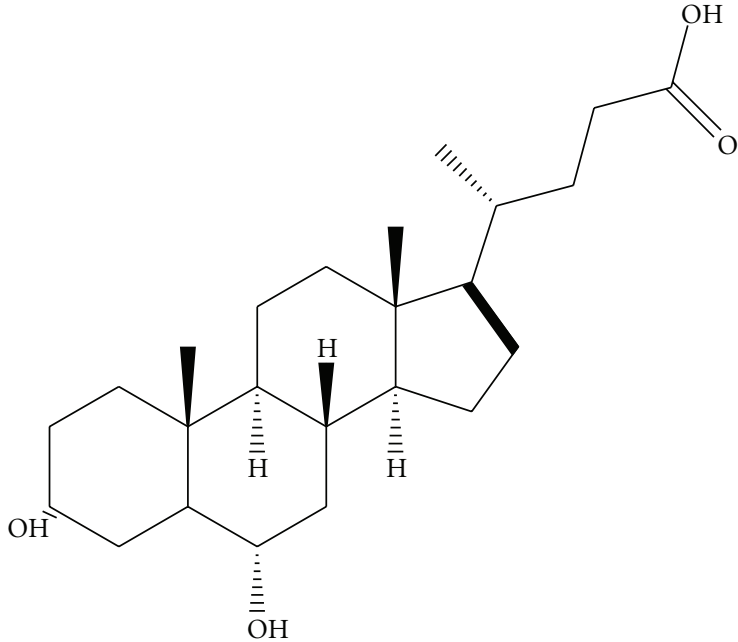

(a) Hyodeoxycholic acid

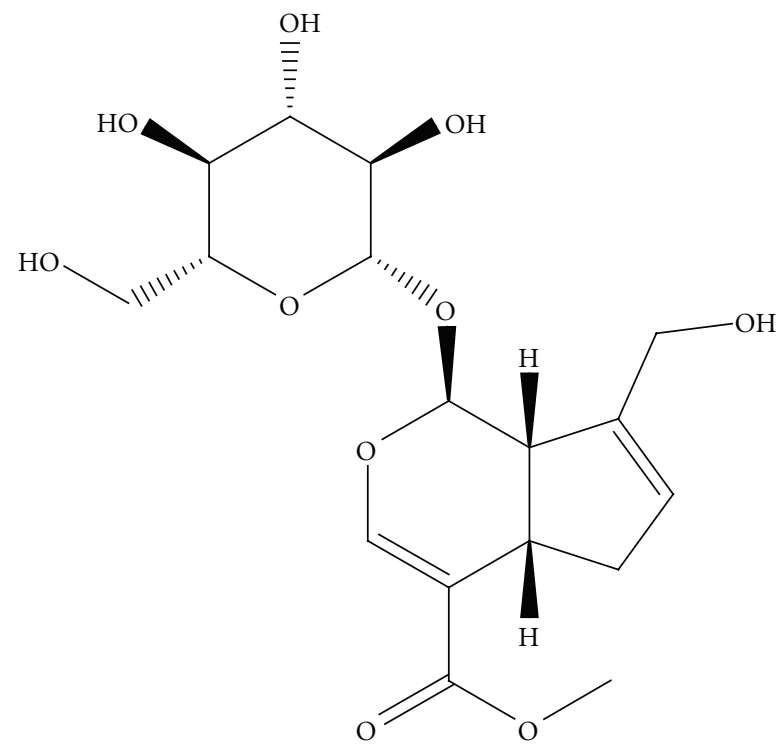

(c) Jasminoidin

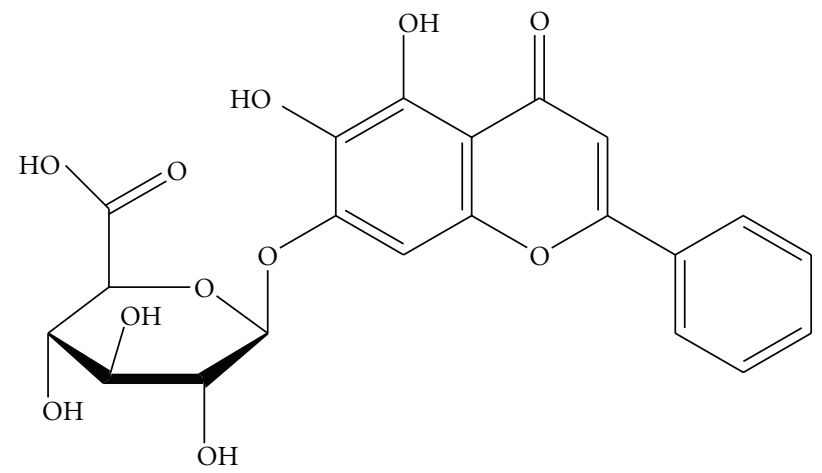

(b) Baicalin

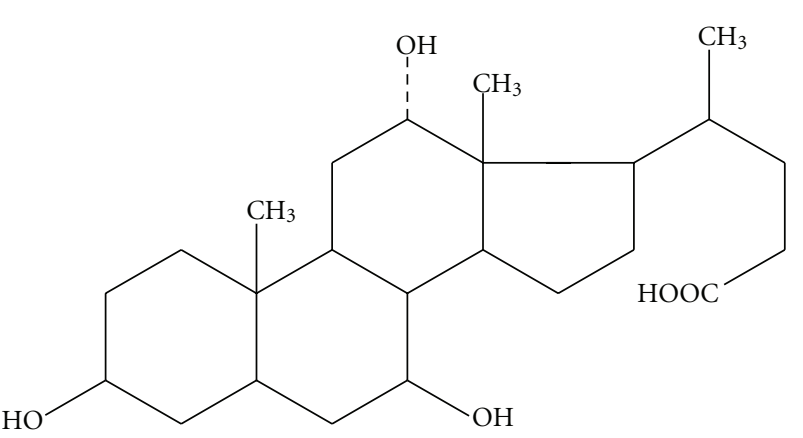

(d) Cholic acid

FIGURE 1: Molecular structure of the four components of RQKL.

the combination of the four components can significantly improve their effectiveness [16].

The endoplasmic reticulum (ER) regulates protein synthesis, protein folding and trafficking, cellular responses to stress, and intracellular calcium levels [17]. The conditions that impair the function of the ER, designated "ER stress", can lead to an accumulation of unfolded proteins in the ER lumen [18]. However, if ER stress is too severe, the unfolded protein response ultimately initiates an apoptotic pathway [19]. ER stress-induced cell death has been shown to involve the activation of caspase-12 [20,21], while another component of the ER stress-mediated apoptotic pathway is elf-2a [22]. Several studies have shown that cerebral ischemia is a pathological ER stressor, which can trigger the shutdown of protein translation and apoptosis, suggesting that ER plays an important role in cerebral ischemia $[23,24]$. Thus, reducing ER stress may provide a therapeutic way to block the pathological process induced by cerebral ischemia $[18$, 24].

This paper is designed to explain the dose effect and therapeutic time window of RQKL on MCAO rodents, as well as to elaborate intervention effect of RQKL on neuron apoptosis due to ER stress after cerebral ischemia.

\section{Materials and Methods}

2.1. Animals. We used 154 healthy, male, Kunming mice weighing 25-28g, and 90 healthy, male, C57BL/6 mice weighing 25-30 g, purchased from Vital River Laboratories, Beijing, China (no. SCXK (Beijing) 2006-0009) and housed in the Central Laboratory, Beijing University of Chinese Medicine on a $12 \mathrm{~h}$ light: dark cycle at $25 \pm 1^{\circ} \mathrm{C}$, with relative humidity of $40-60 \%$ and automatic day-night rhythm, the mice had free access to standard lab chow and tap water. 
Procedures involving animals and their care were conducted in compliance with institutional guidelines in accordance with NIH Guide for the Care and Use of Laboratory Animals, NIH publication no. 85-23, 1985.

2.2. Drugs. QKL injection, composed of cholic acid, Concha Margaritifera Usta (powder), hyodeoxycholic acid, Fructus Gardeniae, Cornu Bubali (powder), Radix Isatidis, baicalin, and Flos Lonicerae [25], was purchased from the Pharmaceutical Factory of Beijing University of Chinese Medicine (no. 813204A). RQKL injection composed of cholic acid, hyodeoxycholic acid, baicalin, and jasminoidin (Figure 1). Proportion and concentration of 4 compositions is consistent with QKL injection. RQKL injection is provided by Prof. Shouying Du, affiliated to School of Chinese Materia Medica, Beijing University of Chinese Medicine.

2.3. MCAO Model Establishment. Mice were anesthetized with $4 \%$ chloral hydrate $(350 \mathrm{mg} / \mathrm{kg}$ ) and kept under heating lamp to maintain the core body temperature at $36.5 \pm 0.5^{\circ} \mathrm{C}$. Under a dissecting microscope (SXE-1, Shanghai Precision Instrument, Shanghai, China), the right common carotid artery, internal carotid artery, and external carotid artery were carefully exposed, and the external carotid artery was coagulated distal to the bifurcation. A $0.16 \mathrm{~mm}$ diameter nylon filament (tip diameter $0.20 \pm 0.01 \mathrm{~mm}$; Beijing Sunbio Biotech, Beijing, China) was inserted through the external carotid artery stump and gently advanced $10 \mathrm{~mm}$ to occlude the origin of the middle cerebral artery $[26,27]$. The body temperature of the animals was maintained at $37^{\circ} \mathrm{C}$. The filament was removed after $1.5 \mathrm{~h}$. Postoperatively, the mice were housed separately. Neurological function was evaluated when the mice were awake [28]; those with scores less than 2 were excluded.

2.4. Grouping of Experimental Animals and RQKL Injection. In the dose-effect experiments, high, moderate, low dose RQKL injection and QKL injection and model groups were injected with $6,3,1.5 \mathrm{~mL} / \mathrm{kg}$ RQKL and $3 \mathrm{~mL} / \mathrm{kg}$ QKL or equal volume of normal saline, respectively, via the tail veins [7]. Both injections were diluted in saline with different concentrations and the final dose injected to each animal was $9 \mathrm{~mL} / \mathrm{kg}$. The first injection was performed immediately after model establishment, followed by administration after $4 \mathrm{~h}$, and once every $12 \mathrm{~h}$ thereafter.

For time window experiments, the model group was injected with normal saline, and each RQKL group with RQKL ( $3 \mathrm{~mL} / \mathrm{kg})$ diluted using normal saline, via the tail vein. In model and $0 \mathrm{~h}$ groups mice, were first injected simultaneously with the middle cerebral artery, was occluding. The other groups received RQKL injections at 1.5, 3, 6, $9 \mathrm{~h}$ after $\mathrm{MCAO}$, followed by a second injection after $4 \mathrm{~h}$, and every $12 \mathrm{~h}$ thereafter [29], Figure 3(A).

2.5. Assessment of Neurological Function after Focal Cerebral Ischemia/Reperfusion Using Clark Scores. Mice neurological function was evaluated using a blind method $24 \mathrm{~h}$ after model establishment. Clark scores [28] include focal and general neurological function, which reflect ischemia fociinduced neurological function injury and general function, respectively. The focal neurological function was scored from $0-28$, and the general function ranged from $0-32$. Normal mice had a score of 0 . High scores reflect severe neurological functional injury.

2.6. Infarct Volume Assessment. Following neurological function evaluation, mice were sacrificed, and the brain was harvested for TTC staining (Nanjing Greensynthesis Biochemical Co., Ltd., Nanjing, Jiangsu, China). The percent of infarct volume out of the entire brain represented the degree of cerebral infarction. Serial coronal sections $(1 \mathrm{~mm}$ thickness) were prepared and soaked in 2\% TTC phosphate buffer at $37^{\circ} \mathrm{C}$ for 10 minutes in the dark. Normal brain tissues were stained red, while infarct tissues were not stained (white). The sections were soaked in $4 \%$ paraformaldehyde phosphate buffer for 30 minutes, arranged in order and scanned (Tsinghua Unisplendour A688, Xi'an, China). Areas of red and white staining were measured using a computer color multimedia image analysis system (Image-Pro Plus6.0, Media Cybernetics, Wyoming, USA). The percent of infarction is given by the equation: \%Infarct volume = Infarct volume/Total volume of slice $\times 100[30,31]$.

2.7. TUNEL Staining. After $24 \mathrm{~h}$ of recovery, the animals were euthanatized and the brain was rapidly removed, frozen, and cut into $20 \mu \mathrm{m}$ slices. Terminal deoxynucleotidyl transferase dUTP nick end labeling (TUNEL) staining was performed using a kit for programmed cell death (In Situ Cell Death Detection Kit, TMR Red, Roche, USA) according to the manufacturer's directions [32]. Sections of prefrontal cortex were collected. Five areas of each section were examined by fluorescence microscope (ZEISS, LSM510 meta, Germany) in the prefrontal cortex of the ischemic hemisphere and TUNEL-positive cells were quantified [18].

2.8. Measurement of ROS Generation. Brain reactive oxygen species (ROS) production was determined using dihydroethidium (DHE) microfluorography [33]. DHE is a cell permeable dye, which can be oxidized into ethidium and other products by superoxide [33, 34]. Animals were sacrificed at $24 \mathrm{~h}$ after MCAO, and the brains were removed, frozen, and sectioned $(20 \mu \mathrm{m}$ thickness $)$ on a cryostat. Sections of prefrontal cortex were collected. A ROS fluorescence detection kit (Genmed, Wyoming, USA) was used. DHE solution was superfused on the brain sections for 60 minutes and fluorescence intensity was detected by fluorescence microscopy (ZEISS, LSM510 meta, Germany). The fluorescence intensities of five different fields of the brain section were averaged and expressed as relative fluorescence units (RFU) [35].

2.9. Western Blot. Mice were sacrificed after $24 \mathrm{~h}$ of cerebral ischemia, the forehead cortex was collected and homogenated in an ice bath. Proteins were separated on sodium dodecyl sulfate polyacrylamide gel electropheresis and transferred to a nitrocellulose membrane. Blots were 


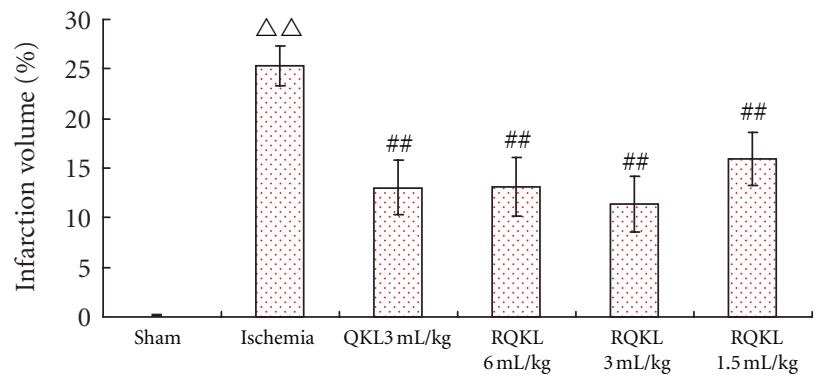

(a)

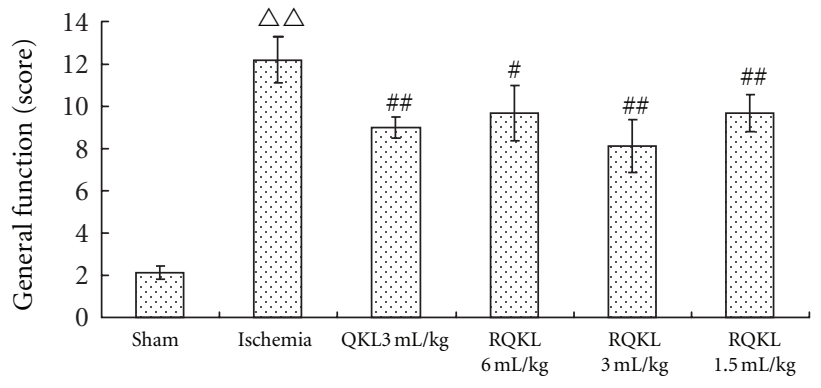

(b)

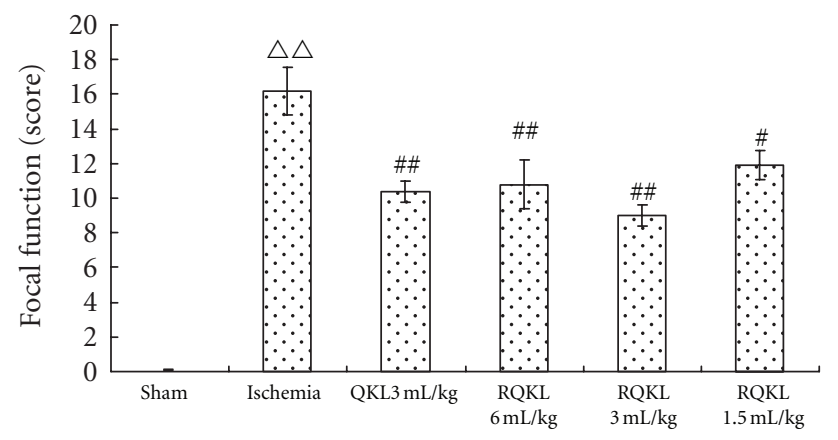

(c)

FIGURE 2: Effect of different doses of RQKL on infarction volume and neurological function of MCAO mouse. Five brain coronal sections, $2 \mathrm{~mm}$ thick, were selected for tetrazolium chloride staining. The infarct volume was quantified as a percentage of total volume, with large infarcts representing more severe injury. The percent of infarct volume was significantly less in RQKL injection groups compared with model group (a). RQKL injection at different doses significantly improve focal and general neurological function (b, c). The scores of focal neurological function and general neurological function were 0 in normal mice. High scores represent severe injury. ${ }^{\Delta \Delta} P<0.01$, versus model group, ${ }^{\#} P<0.05,{ }^{\#} P<0.01$, versus model group. Data are expressed as mean \pm SEM, $n=10$.

blocked with $5 \%$ nonfat dry milk in phosphate buffered saline, $\mathrm{pH}$ 7.6, with $0.1 \%$ Tween-20 buffer and then incubated with antiphospho-eIF2 $\alpha$ (Ser51) polyclonal antibody (Cell Signaling Technology Inc., Tokyo, Japan), anticaspase12 polyclonal antibody (Cell Signaling Technology Inc., Tokyo, Japan), or anti-caspase3 (8G10) polyclonal antibody (Cell Signaling Technology Inc., Tokyo, Japan), subsequently incubated with secondary anti-rabbit antibody conjugated with horseradish peroxidase. Finally, membranes were processed for detection using the ECL system.

2.10. Intracellular Calcium Measurement. Intracellular calcium concentration was measured by flow cytometry using Fluo-3AM fluorescence as described previously [36, 37]. Mice were sacrificed $2 \mathrm{~h}$ after middle cerebral artery occlusion or $10 \mathrm{~h}$ reperfusion after $2 \mathrm{~h}$ of occlusion. Forehead cortex and hippocampus were separated in ice bath and prepared into cell suspension. Cell density was adjusted with D-Hanks solution to about $1 \times 10^{6}$. Suspension was incubated at 37 for 10 minutes, then $2 \mu \mathrm{L} / \mathrm{mL}$ Fluo-3AM dye working solution was added and mixed to uniform. Mixed solution was incubated at $37^{\circ} \mathrm{C}$ for 40 minutes in dark place. Flow cytometry (FACS Calibur, Becton Dickinson, USA) analysis was performed with excitation wavelength $488 \mathrm{~nm}$ and emission wavelength $528 \mathrm{~nm}$. The results are expressed as mean fluorescence intensity (MFI) $[37,38]$.
2.11. Statistical Analysis. Data were analyzed using SPSS 16.0 (SPSS, Chicago, IL, USA). One-way analysis of variance was used followed by post hoc analysis for significance with the Student-Newman-Keuls multiple comparison test. All values are expressed as mean \pm SEM. A value of $P<0.05$ was considered statistically significant.

\section{Results}

\subsection{Dose-Response of RQKL for Focal Cerebral Ischemia/Reperfusion}

3.1.1. Dose-Response Effects on Infarct Volume. Mice with focal cerebral ischemia/reperfusion were injected with different doses of RQKL. Infarct foci were evident in the brain of mice at $24 \mathrm{~h}$ after ischemia/reperfusion. Compared to model group, the infarction size was reduced by 49\%, 48\%, 55\% and $37 \%(P<0.01)$ in QKL and high, moderate, and low dose RQKL injection groups, respectively (Figure 2(a)).

3.1.2. Dose-Response Effects on Neurological Function. Prior to MCAO, scores of focal neurological function and general neurological function were 0 . Mice developed neurological functional injury $24 \mathrm{~h}$ after MCAO; however, QKL and all doses of RQKL ameliorated this injury compared with the 


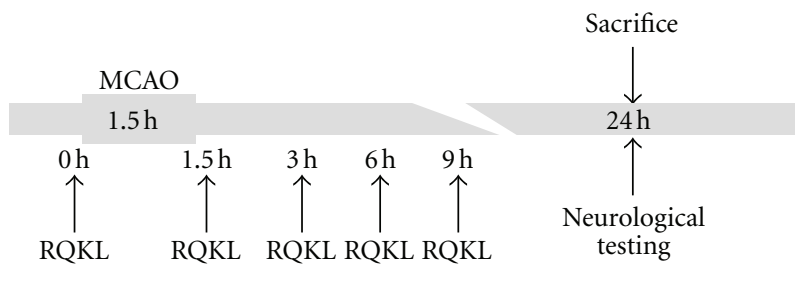

(A)

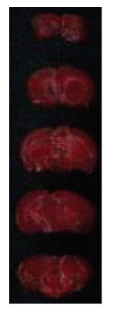

(a)

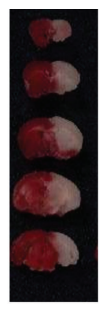

(b)

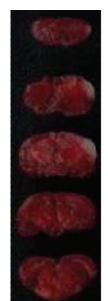

(c)

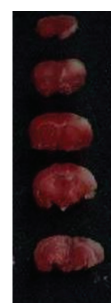

(d)

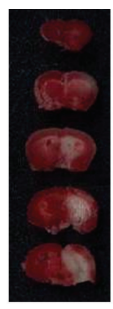

(e)

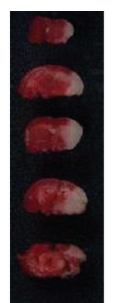

(f)

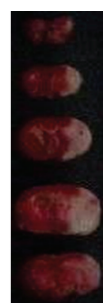

(g)

(B)

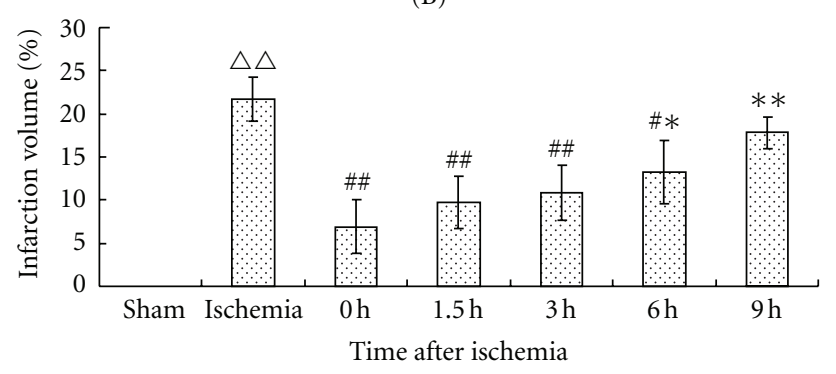

(C)

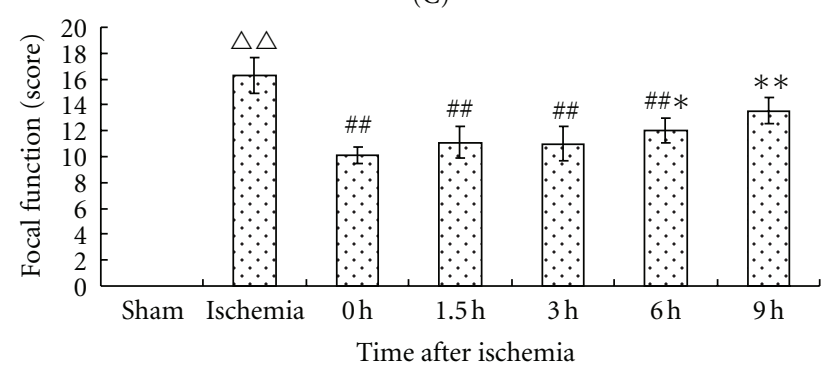

(D)

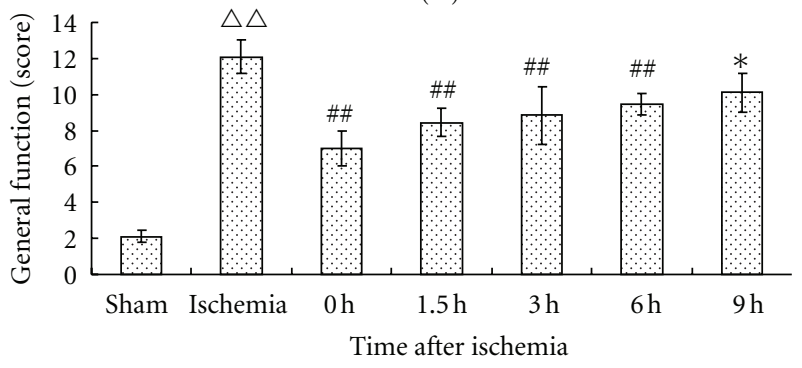

(E)

FIgURE 3: Effects of $R Q K L$ injection at different time points in mice undergoing middle cerebral artery occlusion. Flow chart of time window experiment of RQKL (A). Cerebral infarct volume (B, C) and neurological function scores (D, E) were evaluated $24 \mathrm{~h}$ after brain ischemia. Five brain coronal sections, $2 \mathrm{~mm}$ thick, were selected for tetrazolium chloride staining. Red stain represents normal tissues; white represents the infarct region (B). In panels (D) and (E), high scores represent serious injury. RQKL injection at $0,1.5,3$, or $6 \mathrm{~h}$ after infarction significantly reduced infarct volume and improved focal and general neurological function, but $9 \mathrm{~h}$ group had no effects. ${ }^{\Delta \Delta} P<0.01$, versus model group, ${ }^{\#} P<0.05,{ }^{\#} P<0.01$, versus model group. Data are expressed as mean \pm SEM, the numbers of each group were 10, 11, 12, 9 , $9,12,9$, respectively. 
model group $(P<0.05$ or $P<0.01)$. The results are consistent with our preliminary experiments [29]. The groups receiving the moderate $\mathrm{QKL}$ and $\mathrm{RQKL}$ dose $(3 \mathrm{~mL} / \mathrm{kg})$ exhibited the greatest improvement $(P<0.01)$. Moderate and high dose RQKL injection was able to restore focal neurological function $(P<0.01)$; however, the effect of low dose group was relatively poor $(P<0.05)$, Figures $2(\mathrm{~b})$ and $2(c)$.

\subsection{The Therapeutic Time Window of RQKL}

3.2.1. Cerebral Infarct Volume after Treatment with RQKL at $0,1.5,3,6,9 \mathrm{~h}$ after Ischemia. In preliminary experiment, we found that QKL had a wide therapeutic time window [29]. In this study, RQKL also showed a broad time window. Injection of $3 \mathrm{~mL} / \mathrm{kg}$ RQKL was most effective at reducing infarct volume and improving neurological function, so this dose was used in time window experiments. RQKL injection at $0,1.5,3$, and $6 \mathrm{~h}$ after ischemia significantly reduced cerebral infarct volume $(P<0.01$ or $P<0.05)$. The largest reduction of infarct volume $(68 \%)$ was in the $0 \mathrm{~h}$ group compared with model group $(P<0.01)$. Percent reduction of infarct volume gradually decreased with increasing delay before QKL injection (infarct size: 55\%, 50\%, 39\% in the $1.5,3$, and $6 \mathrm{~h}$ groups, resp.). However, $9 \mathrm{~h}$ group reduced cerebral infarct volume $18 \%$ than model group, but with no significance $(P>0.05)$ (Figures $3(\mathrm{~A})$ and $3(\mathrm{~B}))$.

3.2.2. Neurological Function Scores after Treatment with RQKL at 0, 1.5, 3, 6, 9 h after Ischemia. Consistent with dose-effect experiments, the general and focal neurological functions were significantly improved in the $0 \mathrm{~h}$ group $(P<0.01)$. In other treatment groups, RQKL injected at $1.5,3$, and $6 \mathrm{~h}$ after MCAO significantly enhanced both general and focal neurological functions $(P<0.01)$, but administration at $9 \mathrm{~h}$ was not effective. However, with the first treating time delay, the effects gradually decreased. The focal neurological function of 6 and $9 \mathrm{~h}$ groups were significantly lower than $0 \mathrm{~h}$ group $(P<0.05, P<0.01$, resp.), while general neurological function of $9 \mathrm{~h}$ group was significantly lower than $0 \mathrm{~h}$ group $(P<0.05)$ (Figures $3(\mathrm{C})$ and $3(\mathrm{D}))$.

3.2.3. Effects of RQKL on Neurons Apoptosis. Cellular apoptosis is an important mechanism of nerve injury after brain ischemia/reperfusion [18]. The TUNEL method was used to investigate whether an antiapoptotic effect was involved in the neuroprotection by RQKL. Few apoptotic cells were observed in brain tissues of sham mice. A large number of TUNEL-positive neurons were observed in the prefrontal cortex $24 \mathrm{~h}$ after ischemia. Following QKL $(3 \mathrm{~mL} / \mathrm{kg})$ or RQKL $(6,3$ and $1.5 \mathrm{~mL} / \mathrm{kg})$ injections, the number of TUNEL-positive neurons was reduced significantly (Figures 4(a), 4(b), and 4(c)). This showed that RQKL reduced the number of apoptotic cells in brains of MCAO mice. Meanwhile, the antiapoptosis effect of RQKL showed dosedependence.
3.2.4. Effects of RQKL on Protein Level of Caspase-3, ProCaspase12, and P-eIF2 $\alpha$. Caspase-3 is an important key protein in cell apoptosis. Moreover, it is well known that caspase-3 is induced after ischemic insults [39]. In this study, caspase- 3 in the cortex increased markedly, whereas QKL and RQKL injections noticeably reduced the protein level (Figures 5(a) and 5(b)). Caspase-12 plays a role in apoptotic cell death by ER stress [20]. Therefore, we examined the effects of RQKL treatment on the induction of caspase12 after ischemia. Western blotting analysis showed that caspase-12 was activated $24 \mathrm{~h}$ after hypoxia-ischemia, as evidenced by a decrease in the level of the procaspase-12, which was largely restored by QKL and RQKL (about 50\% restoration compared with the model group) (Figures 5(a) and 5(c)). A key feature of ER stress induced by cerebral ischemia is the blocking of translation at the initiation step, as indicated by increased phosphorylation of eIF $2 \alpha$ $[40,41]$. Therefore, we examined whether RQKL affects the phosphorylation of eIF $2 \alpha$. The level of phospho-eIF $2 \alpha$ in injured cortex was markedly increased $24 \mathrm{~h}$ after ischemia, whereas the injection of QKL or RQKL noticeably reduced the levels of phospho-eIF2 $\alpha$ (approximately 30 to $60 \%$ reduction, compared with the model group) (Figures 5(a) and $5(\mathrm{~d}))$.

3.2.5. Antioxidative Effects of RQKL Injection. Reactive oxygen species production was detected using DHE staining. As shown in (Figures 6(A) and 6(B), no fluorescence was evident in sham mice brain. A large number of fluorescent nerve cells contributed to significantly enhanced fluorescence in the prefrontal cortex at $24 \mathrm{~h}$ after MCAO. Following treatment with QKL and RQKL, the number of fluorescent nerve cells was reduced, and the fluorescence intensity was weakened, indicating that RQKL reduced ROS production. Quantitative analysis showed that fluorescence in the cortex was significantly decreased in all the RQKL doses groups compared with the model group $(P<0.01$, Figure $6(\mathrm{c}))$. This was consistent with our previous work that QKL injection has antioxidative effects [29].

3.2.6. Intracellular Calcium. As shown in Figure 7, intracellular $\mathrm{Ca}^{2+}$ markedly increased $2 \mathrm{~h}$ after ischemia, significantly compared with the sham group $(P<0.01)$, whereas the injection of RQKL noticeably reduced the $\mathrm{Ca}^{2+}$ content. However, for mice suffering $2 \mathrm{~h}$ ischemia following $10 \mathrm{~h}$ reperfusion, only intracellular $\mathrm{Ca}^{2+}$ of hippocampal cells increased, and RQKL did not significantly reduce it. So RQKL only performed modulation effect of intracellular calcium in the early period after ischemia.

\section{Discussion}

QKL injection is a famous Chinese medicine widely used in China for more than thirty years. However, since the National Accident Data Recorder Monitoring Center noticed the first case of anaphylaxis following administration of QKL in November 2001, medical journals have published some case reports about the adverse drug reactions and adverse 


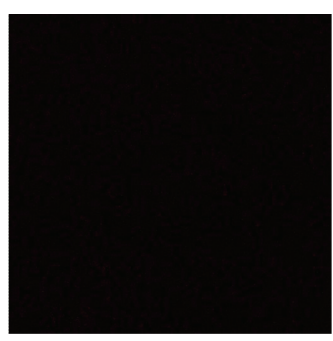

(a)

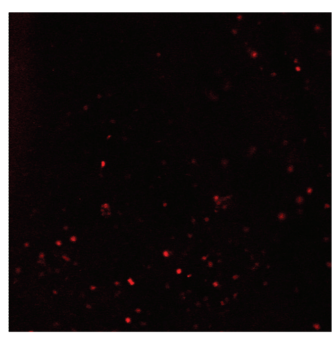

(c)

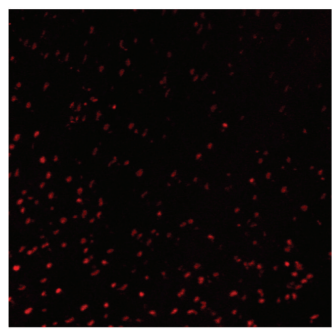

(e)

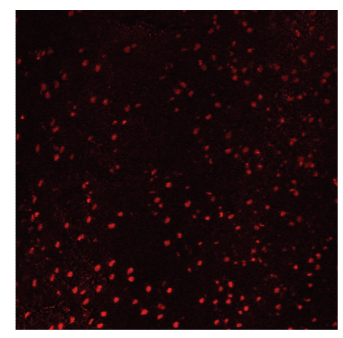

(b)

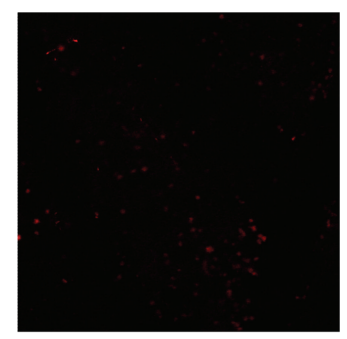

(d)

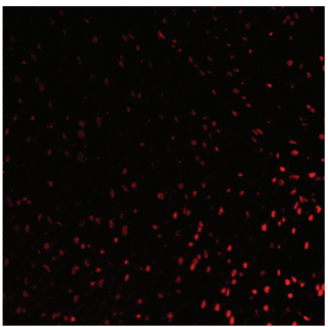

(f)

(A)

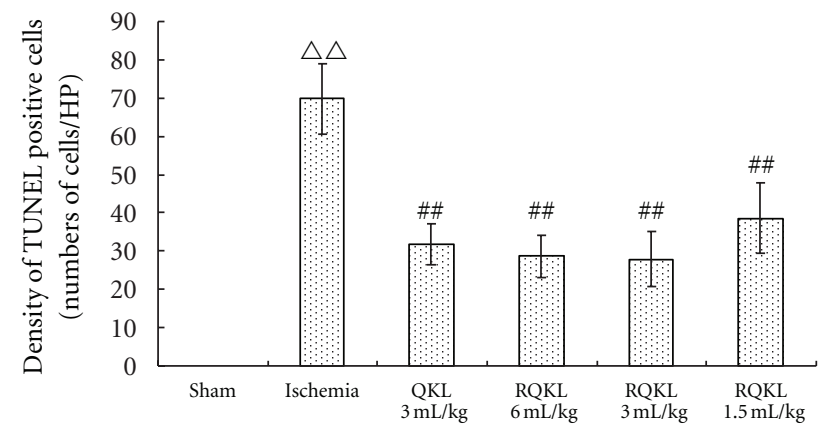

(B)

FIGURE 4: Effect of $R Q K L$ injection on cell apoptosis in prefrontal cortex of mice (TUNEL staining). After middle cerebral artery occlusion for $24 \mathrm{~h}$, apoptotic cells were detected in the prefrontal cortex $((\mathrm{A}), \times 400)$. Apoptotic cells were labeled with red fluorescence. (a) sham, (b) ischemia, c-ischemia+QKL3ml $/ \mathrm{kg}$, d-ischemia+RQKL $6 \mathrm{~mL} / \mathrm{kg}$, (e) ischemia+RQKL3ml $/ \mathrm{kg}$, (f) ischemia+RQKL1.5 mL/kg. Five animals were selected from each group; three sections were selected from each site; and five 400-fold fields of view were randomly selected from each section to quantify the mean of positive cells. Results are expressed as mean \pm SEM (B). ${ }^{\Delta \Delta} P<0.01$, versus sham-surgery group; ${ }^{\# \#} P<0.01$, versus model group. 


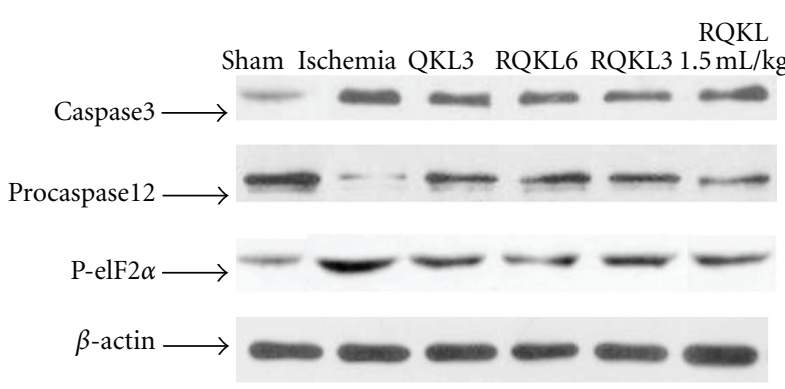

(a)

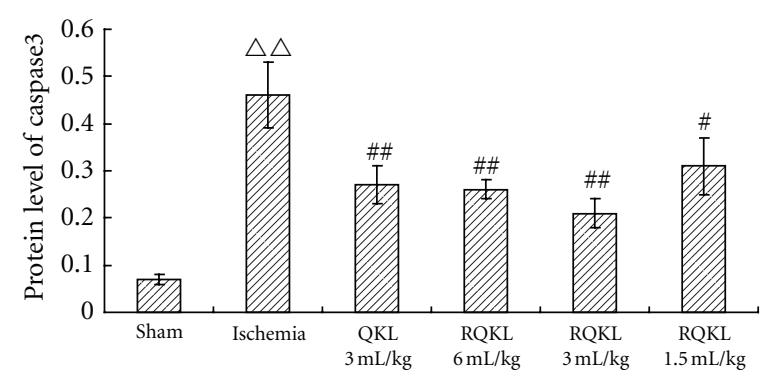

(c)

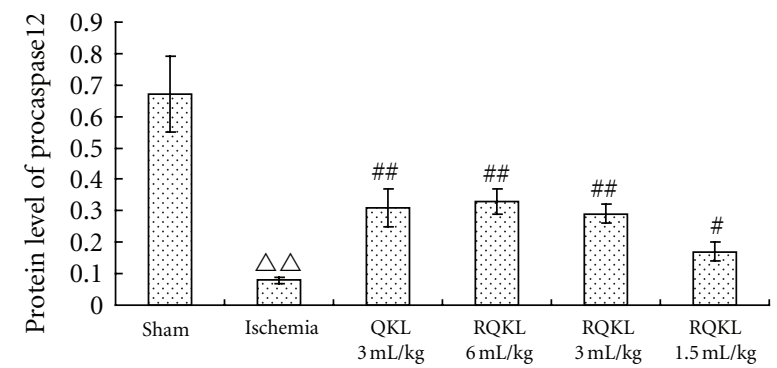

(b)

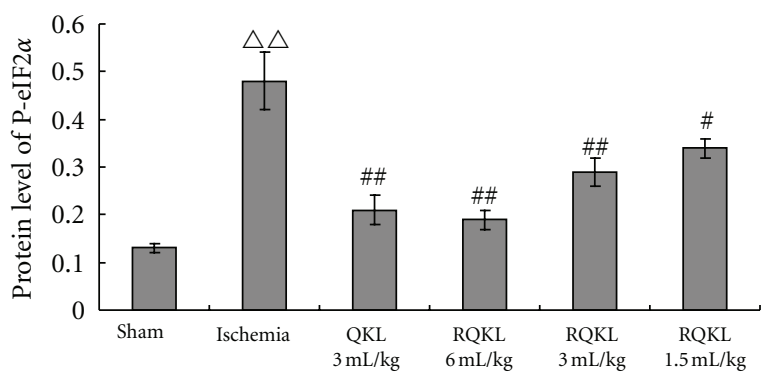

(d)

FIgURE 5: Effect of RQKL on protein levels of caspase3, procaspase12, and P-elF2a in cortex of MCAO mouse. Mice were subjected to $1.5 \mathrm{~h}$ ischemia followed $22.5 \mathrm{~h}$ reperfusion. QKL or RQKL was injected immediately after ischemia. The tissue samples were from the cerebral cortex. The panels are representative Western blotting analyses of caspase3, procaspase12 and P-elF2a. The gray values were calculated, and protein levels were expressed by the ratio of aim protein $/ \beta$-actin as mean \pm SEM. Notes ${ }^{\Delta \Delta} P<0.01$, versus normal, \#\# $P<0.01$, versus ischemia, ${ }^{\#} P<0.05$, versus ischemia, $n=5$. Primary antibodies were diluted, caspase12 $1: 400$, caspase3 1:2000, and P-elF2a 1:500.

events due to its use, so the safety of QKL injections became a focus of public opinion [9]. Much more attention has been attached to drug safety of traditional Chinese medicine (TCM), as well as efficiency. Redeveloping famous Chinese medicine formulas is a new way to improve traditional Chinese medicine, which is important for the modernization and globalization of TCM. Aimed at acute ischemic stroke, one of the indications of QKL, we refined QKL into a novel medicine, namely RQKL. It is composed of only four components of QKL, which has an advantage in quality stabilization and drug safety. In this study, we researched the efficiency and therapeutic time window of RQKL using MCAO mice, compared with QKL. The results showed that the injection of RQKL at doses of $1.5,3,6 \mathrm{~mL} / \mathrm{kg}$ protected the brain from ischemic injury, as evidenced by reductions in infarct volume and neurological function. Most importantly, administration of RQKL provided a wide therapeutic window of $6 \mathrm{~h}$.

The time window in which a drug is effective varies between drugs, commonly ranging between $2-4 \mathrm{~h}$ for ischemic stroke drugs [42-44], but occasionally extended to $12 \mathrm{~h}$ [45]. Administration beyond the therapeutic window can reduce or even abolish the pharmacodynamic action. This present study has defined the therapeutic window for RQKL injection in the treatment of brain ischemia. Incompatible with QKL, RQKL can also significantly reduce infarct volume and improved focal and general neurological function when administered in a broad time window after ischemia. RQKL injection at $6 \mathrm{~h}$ after ischemia significantly reduced infarct volume and improved neurological function, so the therapeutic window for RQKL injection for MCAO mice can be said to extend to over $6 \mathrm{~h}$. This may be profited from multimechanisms of the compound Chinese medicine, for it showed remarkable effects of promoting endothelial nitric oxide synthase expression, reducing calcium overload, regulating matrix metallopeptidase 9 expression and inhibiting inflammation in a murine model of cerebral ischemia/reperfusion [5-8].

In this study, we found that RQKL can effectively suppress apoptosis in vivo. RQKL treatment significantly inhibited apoptosis under in vivo ischemic conditions, as indicated by the results of TUNEL assays. Moreover, the present findings indicated that the protective effect of RQKL on ischemic injury may be medicated in part by restoration of ER dysfunction. Previous studies showed that mitochondria play a central role in neurons apoptosis after ischemia. However, recent studies suggested that ER damage is involved in neuronal cell death induced by cerebral ischemia [23, 24, 46]. In the present study, we investigated the effect of RQKL on ER dysfunction under pathological conditions. Consistent with the results reported in recent years [18, 47], in mice subjected to $1.5 \mathrm{~h}$ ischemia and $22.5 \mathrm{~h}$ reperfusion, we observed an remarkable increase in the level of the eIF $2 \alpha$ phosphorylation in the ischemic cortex, which indicated that ischemia/reperfusion caused severe ER damage. On the other hand, treatment with RQKL significantly inhibited peIF $2 \alpha$ induction. Therefore, the protective effects of RQKL in ischemia/reperfusion injury may be partly due to inhibition of ER stress and subsequent apoptotic signaling pathway. 


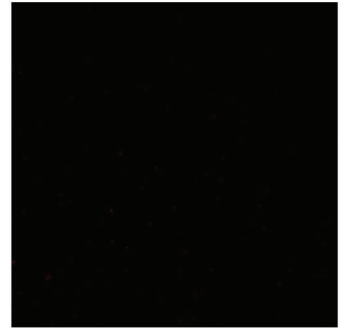

(a)

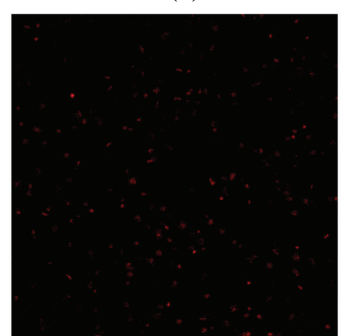

(c)

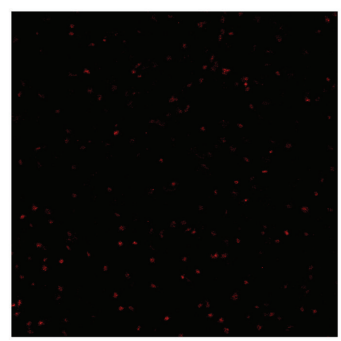

(e)

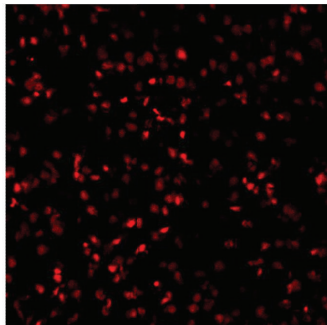

(b)

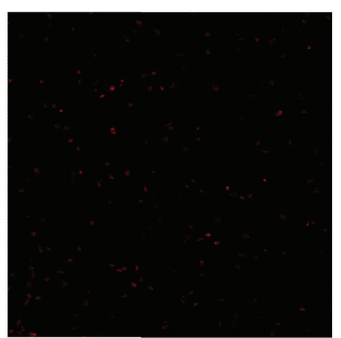

(d)

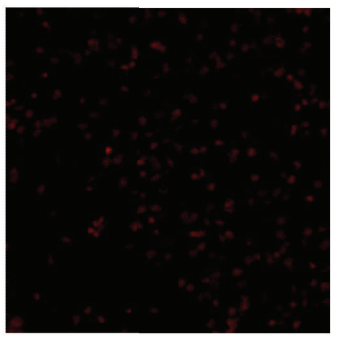

(f)

(A)

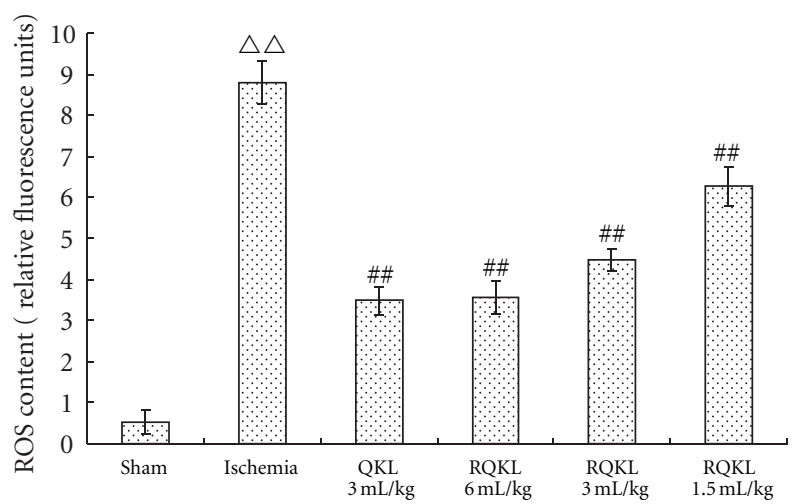

(B)

FIGURE 6: Effects of RQKL injection on reactive oxidative species in mice undergoing middle cerebral artery occlusion. Relative intensity of red fluorescence represents reactive oxygen species (ROS) content in the prefrontal cortex $((\mathrm{A}) \times 200)$ regions of the injured hemisphere. (a) sham, (b) ischemia, (c) ischemia+QKL3ml $/ \mathrm{kg}$, (d) ischemia+RQKL $6 \mathrm{~mL} / \mathrm{kg}$, e-ischemia+RQKL3ml $/ \mathrm{kg}$, (f) ischemia+RQKL1.5 mL/kg. Relative fluorescence intensity in five sites from one section was determined by fluorescence microscopy. The mean value of ROS content was calculated and expressed as mean \pm SEM (B). ${ }^{\Delta \Delta} P<0.01$, versus sham, ${ }^{\#} P<0.01$, versus ischemia, $n=5$. 


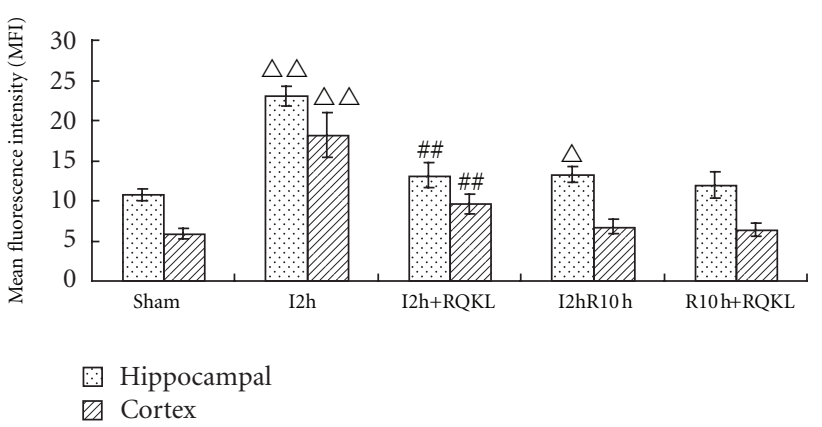

FIgURe 7: Effect of RQKL on intracellular $\mathrm{Ca}^{2+}$ in brain cells. Mice were divided into five groups: sham group, I2h group for cerebral ischemia $2 \mathrm{~h}, \mathrm{I} 2 \mathrm{hR} 10 \mathrm{~h}$ group suffering ischemia $2 \mathrm{~h}$ followed $10 \mathrm{~h}$ reperfusion. RQKL therapeutic group received RQKL $(3 \mathrm{~mL} / \mathrm{kg})$ immediately after ischemia. Neurons of hippocampal and forehead cortex regions were detected by flow cytometry analysis. The results are expressed as mean fluorescence intensity (MFI). Note. ${ }^{\Delta \Delta} P<$ 0.01 , versus sham, ${ }^{\Delta} P<0.05$, versus sham, ${ }^{\#} P<0.01$, versus ischemia, $n=6$.

ER stress-induced cell death has been shown to involve the activation of caspase-12, which subsequently activates executer caspases such as caspase-3 [20, 21, 48, 49]. Caspase12 is specific to insults that elicit ER stress and is not proteolytically activated by other death stimuli [20]. Previous studies have shown that caspase-12 is activated after permanent and transient middle cerebral artery occlusion, and many caspase- 12 positive cells exhibited DNA fragmentation; on the other hand, mice that are deficient in caspase- 12 are more resistant to ER stress-induced apoptosis [20]. This indicated the activation of caspase- 12 is involved in ischemiainduced apoptosis. We found caspase-12 was activated $24 \mathrm{~h}$ after MCAO and RQKL remarkably suppressed the activation, which indicated that RQKL inhibits caspase12 dependent apoptotic pathway. Furthermore, RQKL also decreased caspase-3 level significantly. Caspase-3 activation is involved in caspase-12 mediated apoptotic cascade, while activated caspase- 3 is directly responsible for DNA fragmentation $[20,21,48]$. It is possible that caspase- 3 activation is inhibited by suppression of caspase-12. Thus, RQKL might inhibit caspase-3 activation by suppressing ER stressmediated apoptotic signaling and therefore reduce the extent of apoptosis.

Studies suggested that multiple causes of ER stress occur in neurons following cerebral I/R: intracellular calcium homeostasis, aggregation of proteins, decreased protein degradation, and accumulation of ROS in ER and Golgi structures $[50,51]$. Recent studies suggested that disruption of intracellular calcium homeostasis could induce ER stress and kill cells [52]. In this study, we found intracellular calcium raised markedly $2 \mathrm{~h}$ after ischemia; on the other hand, RQKL can significantly depress intracellular $\mathrm{Ca}^{2+}$. Like intracellular calcium homeostasis, ROS also played an important effect in causing ER stress [51, 53]. RQKL showed excellent antioxidative effects, evidenced by notably reducing ROS. So the inhibition effect to ER stress of RQKL may be immediate or mediated by anti-oxidative as well as intracellular calcium modulation. Considering the findings of the present study, we speculate that RQKL is a promising novel drug for acute ischemia stroke, and it has multiple neuroprotective effects, although the mechanism of its actions needs to be elucidated further.

\section{Abbreviations \\ MCAO: Middle cerebral artery occlusion \\ ROS: Reactive oxygen species \\ ER: Endoplasmic reticulum \\ RQKL: Refined Qingkailing.}

\section{Authors' Contribution}

Q. Wang was in charge of funding and authorized this study. F. Cheng conducted experiments, conceived and designed the study, and wrote the draft of the paper. X. Zhong revised the paper and provided technical support. Y. Lu conducted animal experiments, conceived and designed this study, and participated in paper writing. W. Song and D. Wang contributed to evaluation of the study. S. Guo, X. Wang, D. Liu, and W. Zhao participated in animal experiments and index detections. F. Cheng and X. Zhong equally contributed for this paper.

\section{Conflict of Interests}

The authors declare that they have no conflict of interests.

\section{Acknowledgments}

This study was supported by the Science and Technology Major Projects for Major New Drugs (Qingkailing injection for treatment of ischemic stroke), no. 2009ZX09102-136. The authors thank Shouying Du, School of Chinese Materia Medica, Beijing University of Chinese Medicine, for providing RQKL injection.

\section{References}

[1] M. Fisher, G. Feuerstein, D. W. Howells et al., "Update of the stroke therapy academic industry roundtable preclinical recommendations," Stroke, vol. 40, no. 6, pp. 2244-2250, 2009.

[2] M. Fisher, D. F. Hanley, G. Howard, E. C. Jauch, and S. Warach, "Recommendations from the STAIR V meeting on acute stroke trials, technology and outcomes," Stroke, vol. 38, no. 2, pp. 245-248, 2007.

[3] Beijing University of Chinese Medicine, "The study of novel dosage form of An Gong Niu Huang Wan," Journal of New Medicine, vol. 8, no. 12, 1975.

[4] F. F. Cheng, W. T. Song, and S. Y. Guo, "Meta-analysis of clearing heat and removing toxicity therapy on ischemic stroke," Pharmacology and Clinics of Chinese Materia Medica, vol. 27, no. 1, pp. 106-109, 2011.

[5] X. Chen, O. M. Zack Howard, X. Yang, L. Wang, J. J. Oppenheim, and T. Krakauer, "Effects of Shuanghuanglian and Qingkailing, two multi-components of traditional Chinese medicinal preparations, on human leukocyte function," Life Sciences, vol. 70, no. 24, pp. 2897-2913, 2002. 
[6] S. Yue, Q. Li, S. Liu et al., "Mechanism of neuroprotective effect induced by QingKaiLing as an adjuvant drug in rabbits with E. coli bacterial meningitis," Acta Neurochirurgica, no. 96, pp. 413-418, 2006.

[7] Q. Hua, X. Zhu, P. Li et al., "Refined Qing Kai Ling, traditional Chinese medicinal preparation, reduces ischemic strokeinduced infarct size and neurological deficits and increases expression of endothelial nitric oxide synthase," Biological and Pharmaceutical Bulletin, vol. 31, no. 4, pp. 633-637, 2008.

[8] L. Lv, Y. Liu, H. F. Shi, and Q. Dong, "Qingkailing injection attenuates apoptosis and neurologic deficits in a rat model of intracerebral hemorrhage," Journal of Ethnopharmacology, vol. 125, no. 2, pp. 269-273, 2009.

[9] Y. Hao, X. Kong, and T. Wu, "Assessment of the safety of Qin Kai Ling injection: a systematic review," Journal of EvidenceBased Medicine, vol. 3, no. 2, pp. 105-116, 2010.

[10] X. K. Tu, W. Z. Yang, S. S. Shi, C. H. Wang, and C. M. Chen, "Neuroprotective effect of baicalin in a rat model of permanent focal cerebral ischemia," Neurochemical Research, vol. 34, no. 9, pp. 1626-1634, 2009.

[11] S. H. Jung, K. D. Kang, D. Ji et al., "The flavonoid baicalin counteracts ischemic and oxidative insults to retinal cells and lipid peroxidation to brain membranes," Neurochemistry International, vol. 53, no. 6-8, pp. 325-337, 2008.

[12] J. J. Liu, F. Yin, X. X. Zheng, J. Jing, and Y. Hu, "Geniposide, a novel agonist for GLP-1 receptor, prevents PC12 cells from oxidative damage via MAP kinase pathway," Neurochemistry International, vol. 51, no. 6-7, pp. 361-369, 2007.

[13] J. G. Yang, Y. H. Shen, Y. Hong et al., "Stir-baked Fructus gardeniae (L.) extracts inhibit matrix metalloproteinases and alter cell morphology," Journal of Ethnopharmacology, vol. 117, no. 2, pp. 285-289, 2008.

[14] C. M. P. Rodrigues, S. R. Spellman, S. Solá et al., "Neuroprotection by a bile acid in an acute stroke model in the rat," Journal of Cerebral Blood Flow and Metabolism, vol. 22, no. 4, pp. 463-471, 2002.

[15] Y. Hua, M. R. Kandadi, M. Zhu, J. Ren, and N. Sreejayan, "Tauroursodeoxycholic acid attenuates lipid accumulation in endoplasmic reticulum-stressed macrophages," Journal of Cardiovascular Pharmacology, vol. 55, no. 1, pp. 49-55, 2010.

[16] Z. J. Zhang, P. Li, Z. Wang et al., "A comparative study on the individual and combined effects of baicalin and jasminoidin on focal cerebral ischemia-reperfusion injury," Brain Research, vol. 1123, no. 1, pp. 188-195, 2006.

[17] R. V. Rao, H. M. Ellerby, and D. E. Bredesen, "Coupling endoplasmic reticulum stress to the cell death program," Cell Death and Differentiation, vol. 11, no. 4, pp. 372-380, 2004.

[18] X. Qi, Y. Okuma, T. Hosoi, and Y. Nomura, "Edaravone protects against hypoxia/ischemia-induced endoplasmic reticulum dysfunction," Journal of Pharmacology and Experimental Therapeutics, vol. 311, no. 1, pp. 388-393, 2004.

[19] R. E. Cudna and A. J. Dickson, "Endoplasmic reticulum signaling as a determinant of recombinant protein expression," Biotechnology and Bioengineering, vol. 81, no. 1, pp. 56-65, 2003.

[20] T. Nakagawa, H. Zhu, N. Morishima et al., "Caspase-12 mediates endoplasmic-reticulum-specific apoptosis and cytotoxicity by amyloid- $\beta$," Nature, vol. 403, no. 6765, pp. 98-103, 2000.

[21] S. Wan, P. Shi, X. Zhang, C. Gu, and S. Fan, "Stronger expression of CHOP and caspase 12 in diabetic spinal cord injury rats," Neurological research, vol. 31, no. 10, pp. 1049 1055, 2009.
[22] Y. Inokuchi, Y. Nakajima, M. Shimazawa et al., "Effect of an inducer of BiP, a molecular chaperone, on endoplasmic reticulum (ER) stress-induced retinal cell death," Investigative Ophthalmology and Visual Science, vol. 50, no. 1, pp. 334-344, 2009.

[23] Y. Oida, M. Shimazawa, K. Imaizumi, and H. Hara, "Involvement of endoplasmic reticulum stress in the neuronal death induced by transient forebrain ischemia in gerbil," Neuroscience, vol. 151, no. 1, pp. 111-119, 2008.

[24] C. G. Zou, X. Z. Cao, Y. S. Zhao et al., "The molecular mechanism of endoplasmic reticulum stress-induced apoptosis in PC-12 neuronal cells: the protective effect of insulin-like growth factor I," Endocrinology, vol. 150, no. 1, pp. 277-285, 2009.

[25] China Pharmacopoeia Committee, Pharmacopoeia of the People's Republic of China, Chemical Industry Press, Beijing, China, 2005.

[26] M. G. De Simoni, C. Storini, M. Barba et al., "Neuroprotection by complement (C1) inhibitor in mouse transient brain ischemia," Journal of Cerebral Blood Flow and Metabolism, vol. 23, no. 2, pp. 232-239, 2003.

[27] S. A. Menzies, J. T. Hoff, A. L. Betz, and R. R. Smith, "Middle cerebral artery occlusion in rats: a neurological and pathological evaluation of a reproducible model," Neurosurgery, vol. 31, no. 1, pp. 100-107, 1992.

[28] W. M. Clark, N. S. Lessov, M. P. Dixon, and F. Eckenstein, "Monofilament intraluminal middle cerebral artery occlusion in the mouse," Neurological Research, vol. 19, no. 6, pp. 641648, 1997.

[29] F. F. Cheng, W. T. Song, X. G. Zhong et al., "Therapeutic window of Qingkailing injection for focal cerebral ischemia/reperfusion injury," Neural Regeneration Research, vol. 6, no. 21, pp. 1605-1611, 2011.

[30] Y. Numagami and S. T. Ohnishi, "S-allylcysteine inhibits free radical production, lipid peroxidation and neuronal damage in rat brain ischemia," Journal of Nutrition, vol. 131, no. 3, pp. 1100S-1105S, 2001.

[31] K. S. Bora and A. Sharma, "Evaluation of antioxidant and cerebroprotective effect of Medicago sativa linn. against ischemia and reperfusion insult," Evidence-Based Complementary and Alternative Medicine, vol. 2011, Article ID 792167, 9 pages, 2011.

[32] H. Li, L.-L. Cai, J.-G. Liu et al., "Effect of early intervention with extract of Huannao Yicong Decoction on the pathologic picture of hippocampus and neurocyte apoptosis in APP transgenic mice model of dementia," Chinese Journal of Integrative Medicine, vol. 17, no. 6, pp. 430-435, 2011.

[33] V. P. Bindokas, J. Jordán, C. C. Lee, and R. J. Miller, "Superoxide production in rat hippocampal neurons: selective imaging with hydroethidine," Journal of Neuroscience, vol. 16, no. 4, pp. 1324-1336, 1996.

[34] H. Girouard, L. Park, J. Anrather, P. Zhou, and C. Iadecola, "Cerebrovascular nitrosative stress mediates neurovascular and endothelial dysfunction induced by angiotensin II," Arteriosclerosis, Thrombosis, and Vascular Biology, vol. 27, no. 2, pp. 303-309, 2007.

[35] H. Girouard, G. Wang, E. F. Gallo et al., "NMDA receptor activation increases free radical production through Nitric Oxide and NOX2," Journal of Neuroscience, vol. 29, no. 8, pp. 2545-2552, 2009.

[36] E. J. Novak and P. S. Rabinovitch, "Improved sensitivity in flow cytometric intracellular ionized calcium measurement using Fluo-3/Fura red fluorescence ratios," Cytometry, vol. 17, no. 2, pp. 135-141, 1994. 
[37] Q. Xie, V. I. Khaoustov, C. C. Chung et al., "Effect of tauroursodeoxycholic acid on endoplasmic reticulum stressinduced caspase-12 activation," Hepatology, vol. 36, no. 3, pp. 592-601, 2002.

[38] T. S. Ma, D. L. Mann, J. H. Lee, and G. J. Gallinghouse, "SR compartment calcium and cell apoptosis in SERCA overexpression," Cell Calcium, vol. 26, no. 1-2, pp. 25-36, 1999.

[39] J. M. Adams, "Ways of dying: multiple pathways to apoptosis," Genes and Development, vol. 17, no. 20, pp. 2481-2495, 2003.

[40] T. Mengesdorf, C. G. Proud, G. Mies, and W. Paschen, "Mechanisms underlying suppression of protein synthesis induced by transient focal cerebral ischemia in mouse brain," Experimental Neurology, vol. 177, no. 2, pp. 538-546, 2002.

[41] D. J. DeGracia, R. Kumar, C. R. Owen, G. S. Krause, and B. C. White, "Molecular pathways of protein synthesis inhibition during brain reperfusion: implications for neuronal survival or death," Journal of Cerebral Blood Flow and Metabolism, vol. 22, no. 2, pp. 127-141, 2002.

[42] H. N. David, B. Haelewyn, C. Rouillon et al., "Neuroprotective effects of xenon: a therapeutic window of opportunity in rats subjected to transient cerebral ischemia," FASEB Journal, vol. 22, no. 4, pp. 1275-1286, 2008.

[43] E. J. Lee, Y. C. Hung, H. Y. Chen, T. S. Wu, and T. Y. Chen, "Delayed treatment with carboxy-ptio permits a 4$\mathrm{h}$ therapeutic window of opportunity and prevents against ischemia-induced energy depletion following permanent focal cerebral ischemia in mice," Neurochemical Research, vol. 34, no. 6, pp. 1157-1166, 2009.

[44] J. Jia, X. Zhang, Y. S. Hu et al., "Protective effect of tetraethyl pyrazine against focal cerebral ischemia/reperfusion injury in rats: therapeutic time window and its mechanism," Thrombosis Research, vol. 123, no. 5, pp. 727-730, 2009.

[45] C. Wang, J. L. Liu, H. F. Sang, Y. Lu, H. L. Dong, and L. Z. Xiong, "Therapeutic time window of flurbiprofen axetil's neuroprotective effect in a rat model of transient focal cerebral ischemia," Chinese Medical Journal, vol. 121, no. 24, pp. 25722577, 2008.

[46] S. Tajiri, S. Oyadomari, S. Yano et al., "Ischemia-induced neuronal cell death is mediated by the endoplasmic reticulum stress pathway involving CHOP," Cell Death and Differentiation, vol. 11, no. 4, pp. 403-415, 2004.

[47] R. Kumar, G. S. Krause, H. Yoshida, K. Mori, and D. J. DeGracia, "Dysfunction of the unfolded protein response during global brain ischemia and reperfusion," Journal of Cerebral Blood Flow and Metabolism, vol. 23, no. 4, pp. 462471, 2003.

[48] T. Mengesdorf, C. G. Proud, G. Mies, and W. Paschen, "Mechanisms underlying suppression of protein synthesis induced by transient focal cerebral ischemia in mouse brain," Experimental Neurology, vol. 177, no. 2, pp. 538-546, 2002.

[49] Z. Z. Wu, Y. H. Li, A. C. J. Huang et al., "Endoplasmic reticulum stress induced by tunicamycin and antagonistic effect of Tiantai No.1 on mesenchymal stem cells," Chinese Journal of Integrative Medicine, vol. 16, no. 1, pp. 41-49, 2010.

[50] J. M. Adams, "Ways of dying: multiple pathways to apoptosis," Genes and Development, vol. 17, no. 20, pp. 2481-2495, 2003.

[51] D. J. DeGracia and H. L. Montie, "Cerebral ischemia and the unfolded protein response," Journal of Neurochemistry, vol. 91, no. 1, pp. 1-8, 2004.

[52] S. Oyadomari and M. Mori, "Roles of CHOP/GADD153 in endoplasmic reticulum stress," Cell Death and Differentiation, vol. 11, no. 4, pp. 381-389, 2004.
[53] W. Paschen, T. Mengesdorf, S. Althausen, and S. Hotop, "Peroxidative stress selectively down-regulates the neuronal stress response activated under conditions of endoplasmic reticulum dysfunction," Journal of Neurochemistry, vol. 76, no. 6, pp. 1916-1924, 2001. 


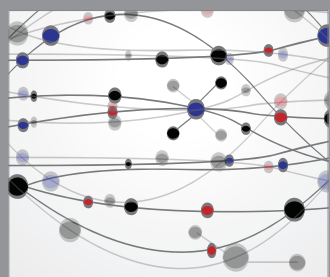

The Scientific World Journal
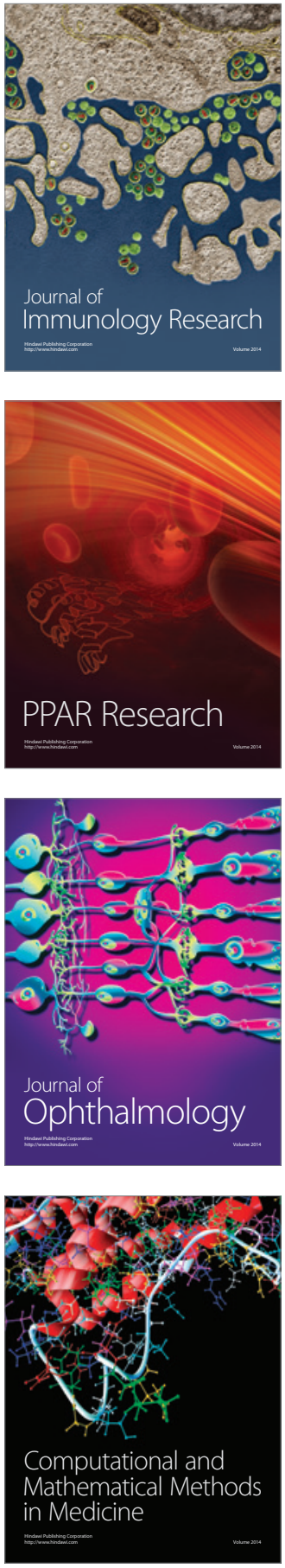

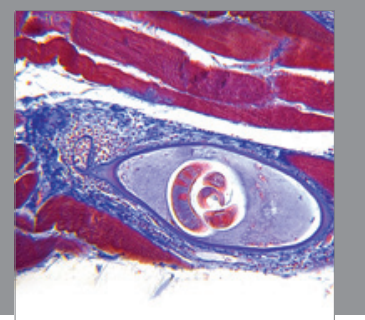

Gastroenterology

Research and Practice
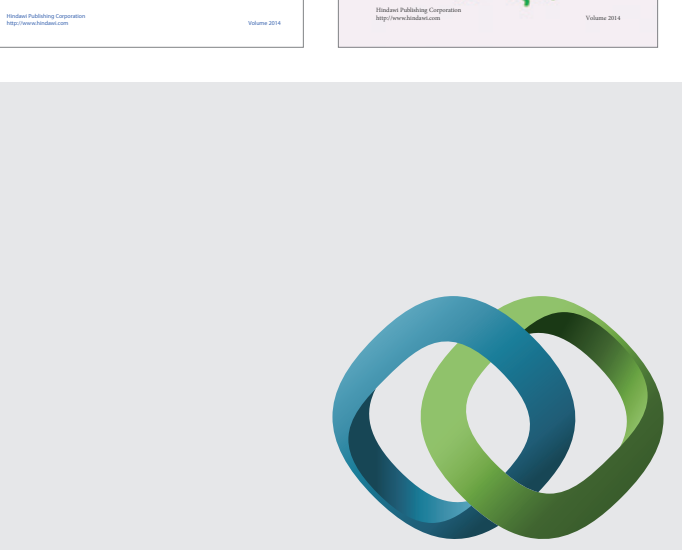

\section{Hindawi}

Submit your manuscripts at

http://www.hindawi.com
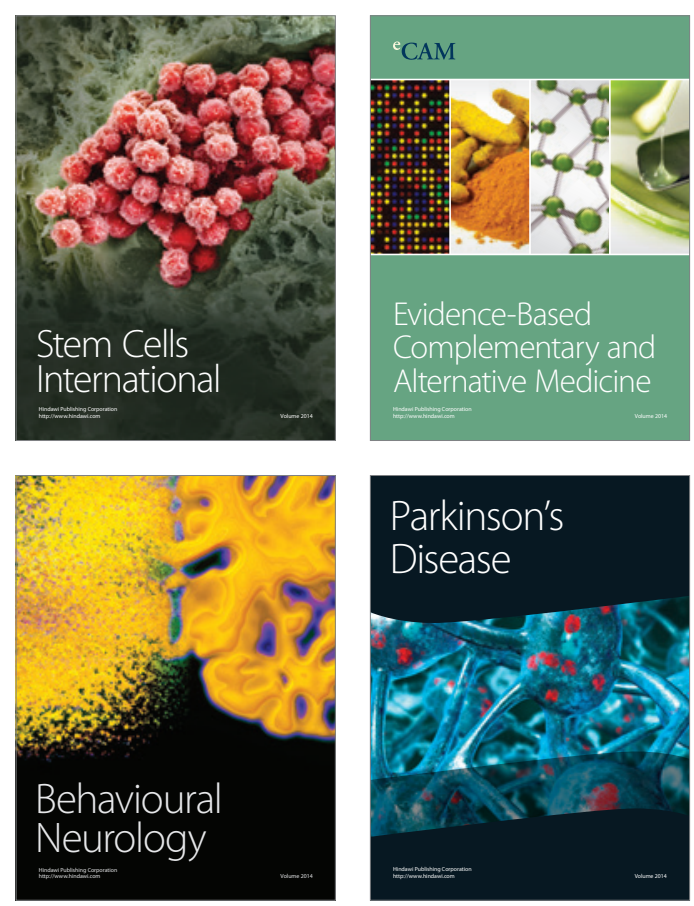

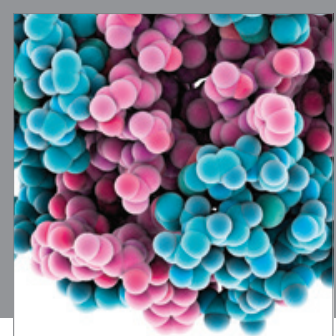

Journal of
Diabetes Research

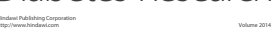

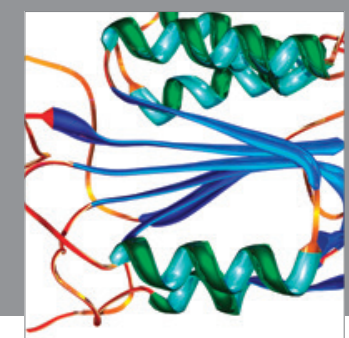

Disease Markers
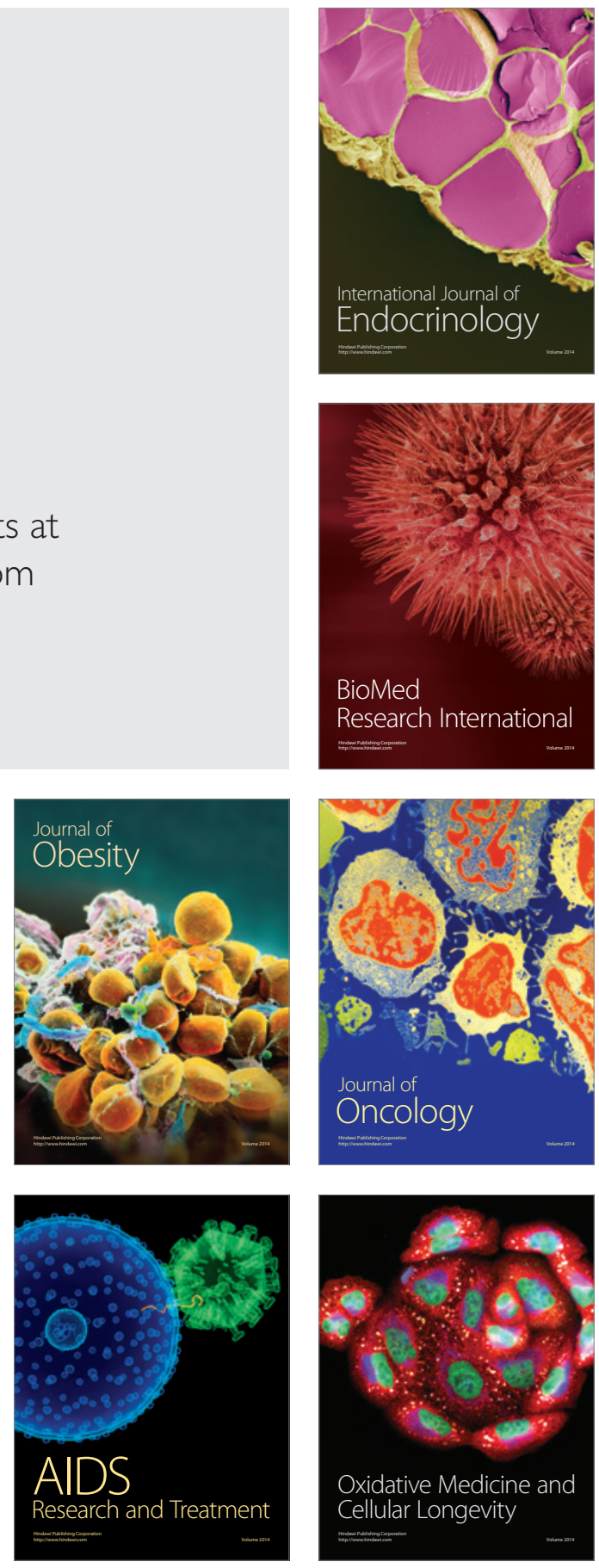